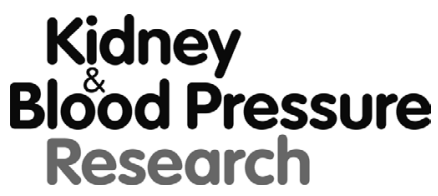

Kidney Blood Press Res 2018;43:1636-1645

DOI: $10.1159 / 000494678$

Published online: 29 October 2018

(C) 2018 The Author(s)

Published by S. Karger AG, Basel

Accepted: 19 October 2018

This article is licensed under the Creative Commons Attribution-NonCommercial-NoDerivatives 4.0 International License (CC BY-NC-ND) (http://www.karger.com/Services/OpenAccessLicense). Usage and distribution tional License (CC BY-NC-ND) (http://www.karger.com/Services/OpenAccessLicense). Usage and dist

\title{
Results of Fabry Disease Screening in Male Pre-End Stage Renal Disease Patients with Unknown Etiology Found Through the Platform of a Chronic Kidney Disease Education Program in a Northern Taiwan Medical Center
}

\author{
Cheng-Jui Lin ${ }^{\mathrm{a}, \mathrm{b}}$ Yin-Hsiu Chien ${ }^{c}$ Thung-S. Lai ${ }^{\mathrm{d}}$ Hong-Mou Shih ${ }^{\mathrm{a}}$ \\ Yi-Chou Chen ${ }^{a}$ Chi-Feng Pan ${ }^{a}$ Han-Hsiang Chen ${ }^{a, b}$ Wuh-Liang Hwu ${ }^{c}$ \\ Chih-Jen $\mathrm{Wu}^{\mathrm{a}, \mathrm{e}, \mathrm{f}}$
}

\begin{abstract}
aDivision of Nephrology, Department of Internal Medicine, Mackay Memorial Hospital, Taipei, bMackay Junior College of Medicine, Nursing and Management, Taipei, 'Department of Medical Genetics, National Taiwan University Hospital, Taipei, ${ }^{\mathrm{d}}$ Graduate Institute of Biomedical Science, Mackay Medical

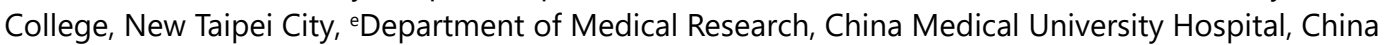
Medical University, Taichung, ${ }^{f}$ Graduate Institute of Medical Sciences and Department of Pharmacology, School of Medicine, College of Medicine, Taipei Medical University, Taipei, Taiwan
\end{abstract}

\section{Key Words}

Fabry disease $\bullet$ Chronic kidney disease $•$ High-risk screening

\begin{abstract}
Background/Aims: Fabry disease (FD), a rare $x$-lined genetic disorder is a cause of renal deterioration. The phenotype of FD is highly variable and nonspecific, and correct diagnosis has always been delayed. We aimed to explore the prevalence and clinical presentation of FD in this high-risk male population in a Northern Taiwan medical center. Methods: This is the first study to survey the incidence of FD in this high-risk population through the platform of a chronic kidney disease (CKD) education program in Asia. A total of 1,012 male patients with unknown CKD causes were screened using an assay of alpha-galactosidase $A$ activity ( $\alpha-G a l A)$ by dried blood spots (DBS). A final GLA gene analysis was also done for those with low enzyme activity. Results: We identified two new patients with classic FD and four patients with lateonset FD. One novel GLA mutation with c.413 G>A was found in one classic FD patient (index 5). The prevalence of FD is about $0.59 \%(6$ in 1,012) in the high-risk population group with CKD. The clinical symptoms of FD patients are nonspecific except in those with various degrees of renal failure. Those patients' correct diagnosis was delayed, taking years and even decades.




\section{Kidney Blood Pressure Research}

Lin et al.: Fabry Disease in Pre-ESRD

Three patients received enzyme replacement therapy and one started regular hemodialysis due to persistent renal function deterioration. Another two patients were found from family screening through a new index. In addition, a false negative result occurred in one patient who was proved to have FD by his kidney pathology as determined by this screening. Conclusion: FD is not such as rare a disease and its prevalence is greater in this high-risk male population. Clinicians need to be aware that FD should be included in the differential diagnosis in CKD with unknown etiology.

(C) 2018 The Author(s)

Published by S. Karger AG, Basel

\section{Introduction}

Fabry disease (FD) is an X-linked lysosomal storage disorder that leads to excessive deposition of glycosphingolipids in the vascular endothelium and in the epithelial and smooth muscle cells of multiple organs due to deficient activity of the lysosomal enzyme $\alpha$-galactosidase A ( $\alpha$-Gal A) resulting from mutations in the GLA gene (Xq21.3-q22) [1,2]. Progressive endothelial accumulation of glycosphingolipids accounts for the associated clinical abnormalities, including neurological pain [3], angiokeratoma [4], proteinuria [5], renal failure [6], ventricular hypertrophy [7], arrhythmia [8], and cerebral infarction [9]. Although the clinical manifestations of FD reflect the cellular sites of globotriaosylceramide (Gb3) storage, the symptoms are heterogeneous among patients, making a timely diagnosis a challenge. Thus, correct diagnosis has typically been delayed for years and even decades.

Patients who experience a stroke at a young age, cardiomyopathy and renal failure with unknown etiology have been regarded as the groups at high risk for FD. The early renal manifestation in patients with the classic phenotype is proteinuria or a decreased glomerular filtration rate. These manifestations progress over time, eventually leading to end-stage renal disease (ESRD) in nearly all male patients $[5,6,10]$. The prevalence of FD in dialysis populations has been explored in several screening studies that have shown that the prevalence may be higher in patients on hemodialysis (HD) than in the general population [11-13]. The highest value up to $1.2 \%$ has been reported in a Japanese study [14]. Thus, FD is a potential cause of ESRD in patients with unknown etiology.

Recent evidence has shown that the progression of FD may be attenuated by enzyme replacement therapy, and clinicians should be aware of the importance of early diagnosis of FD and understand its comorbidities [15]. Prevention of CKD patients from rapid progression to ESRD is a serious public health issue worldwide. However, the actual incidence of FD in the population of CKD patients not on dialysis remains unclear. The prevalence of ESRD patients receiving renal replacement therapy in Taiwan is the highest in the world [16]. In order to reduce the burden of dialysis, Taiwan's Health Promotion Administration established the nationwide CKD Preventive Project with a multidisciplinary care program, early CKD and Pre-ESRD, in 2013. Therefore, this study aimed to investigate the prevalence and clinical presentation of FD in the high-risk male group of Pre-ESRD patients by using the platform of an education program in a medical center in Northern Taiwan.

\section{Materials and Methods}

CKD patients

This study is a cross-sectional analytical study to investigate the prevalence of FD in high risk population. The enzymatic activity can be normal or slightly lower in female FD patients. In order to avoid having high false-negative results using dry blood spots (DBS) in this screening study, female patients were excluded. A total of 1, 012 male patients, with stable CKD (stage 1-5) attending the early CKD or Pre-ESRD education program in our institution's outpatient department, were screened for FD from July 2015 to November 2017. The classification of CKD was based on the criteria of the Kidney Disease: Improving Global Outcomes (KDIGO) (2012) Clinical Practice Guidelines. Patients with a definite diagnosis of renal failure, or those who 


\section{Kidney Blood Pressure Research}

Kidney Blood Press Res 2018;43:1636-1645

\begin{tabular}{l|l}
\hline DOI: $10.1159 / 000494678$ & (c) 2018 The Author(s). Published by S. Karger AG, Basel
\end{tabular}

Published online: 29 October 2018

www.karger.com/kbr

Lin et al.: Fabry Disease in Pre-ESRD

were younger than 18 years of age were excluded from the study. The definite etiology of CKD was assayed by independent nephrologists based on physical examination, past history, family history and biochemical data. A combined enzymatic and confirming genetic assay were used to examine the activity of $\alpha$-Gal A and the GLA genotype in dried blood and whole blood samples, respectively. In short, the male patients met the criteria of unknown CKD cause were enrolled and screened for FD by using DBS. If the initial result from DBS showed low $\alpha$-Gal A activity, genetic analysis was further done to confirm the diagnosis of FD. Subsequently, a series of biochemistry and cardiac examination was arranged for patients with FD. Kidney biopsy was also suggested if patients agreed. The study was performed according to the principles of the Declaration of Helsinki, and approved by the ethics committee of the Mackay Memorial Hospital in Taiwan.

\section{$\alpha$-Galactosidase A Activity assay}

To determine GLA activities of males by DBS, assays were carried out as previously described by the biochemical lab in the National Taiwan University hospital $[17,18]$. Two other enzyme activities, neutral $\alpha$-Glucosidase (NAG) and $\beta$-galactosidase (BGAL), served as a control enzyme to monitor the sample quality and quantity. In the first screening, both GLA and NAG activities were measured from the first DBS samples. The NAG/GLA activity ratio (the ratio) was determined (normal mean \pm SD) of NAG:19.29 \pm 6.15 ; of GLA $4.75 \pm 1.80$, range of the ratio: 2.01-8.62. For samples with the NAG/GLA ratio $>15$ in the first DBS, the second DBS assays were performed on the same sample for GLA activity using BGAL as the control. For samples with a BGAL/GLA ratio $>15$, the respective patients were recalled for confirmatory enzyme and gene tests with blood samples. The cutoffs were intended to detect only patients with classical FD but not variants of FD who have higher residual GLA activity. As of Nov 2016, the GLA activity was detected by the MS/MS method [19] and alpha-L-iduronidase (IDUA) was used as the control enzyme in duplication. The cutoff IDUA/GLA ratio (the ratio) $>10$ was set for confirmatory assays (normal mean \pm SD) of IDUA: $9.03 \pm$ 3.57; of GLA $4.07 \pm 1.76$; range of the ratio: 0.94-5.46.

\section{Molecular Analysis of the $\alpha$-GLA Gene}

Primers for polymerase chain reaction (PCR) were designed to amplify DNA fragments to span all 7 exons and IVS4. The nucleotide sequence of the GLA gene was obtained from GenBank Accession Number NG_007119.1 (sequences of the primers are available on request). As a result, a total of 8 amplicons were used to sequence the coding regions and a specific region of intron4. For PCR amplification, 100$200 \mathrm{ng}$ of the DNA was added to a 48- $\mu \mathrm{L}$ master mix and the amplification was carried out in 38 cycles $\left(94^{\circ} \mathrm{C}\right.$ for 1 minute; $63^{\circ} \mathrm{C}$ for 1 minute; $72^{\circ} \mathrm{C}$ for 1 minute) with 10 pmol primers and $1 \mathrm{U}$ Ampli Taq Gold DNA polymerase (Thermo Fisher). PCR products were purified with the QIA quick PCR Purification Kit (Qiagen). The sequencing reaction of the PCR products was performed using the Big Dye Terminator v3.1 Cycle Sequencing Kit and the further automated capillary electrophoresis was carried out by ABI PRISM 3130 Genetic Analyzer (Applied Bio systems) according to the manufacturer's instructions. To confirm the presence of a particular mutation, sequencing with the reverse primer was performed using the same PCR product if a variant was detected. The sequence variants found were checked to determine whether they had been reported in the database such as HGMD, NCBI Pub Med and "fabry-database.org." A polymorphism was defined as a $>1 \%$ variant frequency in an unaffected population.

\section{Laboratory analysis and data collection}

Patients' age, gender and arterial blood pressure were recorded and measured. Demographic data, patients' history, and other laboratory results were also reviewed from their medical charts. A general physical examination was also done concurrently. Heparinized blood samples from the patients were collected and prepared by cold centrifugation within 30 minutes of blood collection and sent for basic biochemistry analysis. In addition, urinalysis and daily urinary protein losses were also measured.

\section{Cardiac Evaluation and Kidney Histology}

Cardiac evaluation consisted of a 12-lead electrocardiogram, echocardiogram, and magnetic resonance imaging (MRI). A transthoracic 2-dimensional color Doppler echocardiogram was done by experienced cardiologists. It was arranged that all patients with cardiac variant FD undergo cardiac MRI, except those with low GFR. Only 2 patients (index patient 3 and index patient 5) agreed to undergo a percutaneous kidney 


\section{Kidney \\ Blood Pressure \\ Research}

biopsy guided by ultrasonography to investigate the pathogenesis. A kidney biopsy was performed before ERT initiation. An experienced nephropathologist assessed the samples using light, immunofluorescence, and electron microscopy.

\section{Statistical Analyses}

Data are shown as mean \pm standard deviation for the positive cases. The prevalence of FD was calculated by dividing the number of affected individuals by the number of patients in whom FD was screened.

\section{Results}

\section{Patient selection}

A total of 2, 512 patients at different CKD stages and not on dialysis joined the early CKD or Pre-ESRD program at the nephrology clinic in a medical center located in Taipei, Taiwan, from July 2015 to Nov 2017. There were 1050 female CKD patients. Some 450 patients had definite CKD causes including 444 with diabetic nephropathy, 3 with ADPKD and 3 with lupus nephritis. Finally, a total of 1, 012 patients at different CKD stages were initially screened for FD by assay of plasma $\alpha$-Gal A activity with DBS. These patients ranged from 20 to 85 years of age. Fig. 1 illustrates the flow diagram for FD screening in a male CKD population.

\section{$\alpha$-Gal $A$ activity and genotype analysis}

Of these screened negative cases, the mean $\alpha$-Gal A enzyme activity in DBS was 3.097 $\pm 1.76 \mu \mathrm{mol} / \mathrm{L} \mathrm{wb} / \mathrm{hr}$ (Fig. 2). In total, 5 patients were found to be positive (low enzyme activity) and this was further confirmed by genetic analysis. We identified two new patients with classic FD (index patient 4 and 5, c.1228A $>$ G (p.T410A) and c.413G>A (p.G138E), respectively) and three lateonset FD (c.639+919G $>$ A) (index patient 1,2 , and 6$)$. In addition, one false negative result occurred in index patient 3 who has GLA mutation as p.P210S and finally proved to have FD by kidney pathology (Fig. 3). The overall positive rate in male CKD patients with an unknown cause for FD screening was about 0.59 $\%$. In this study, GLA mutation with c.413G $>$ A in index patient 5 was a novel missense mutation for classic FD in Asia.

\section{Phenotypic characterization}

We identified two patients with classic FD and four patients with late-onset FD from this study. The characteristics and history of these detected index patients are listed in Table 1. The mean age of the 6 index patients was $52.2 \pm 21.4$ years and the average eGFR was $50.5 \pm 28.0$ $\mathrm{mL} / \mathrm{min}$. These patients had various degrees of proteinuria

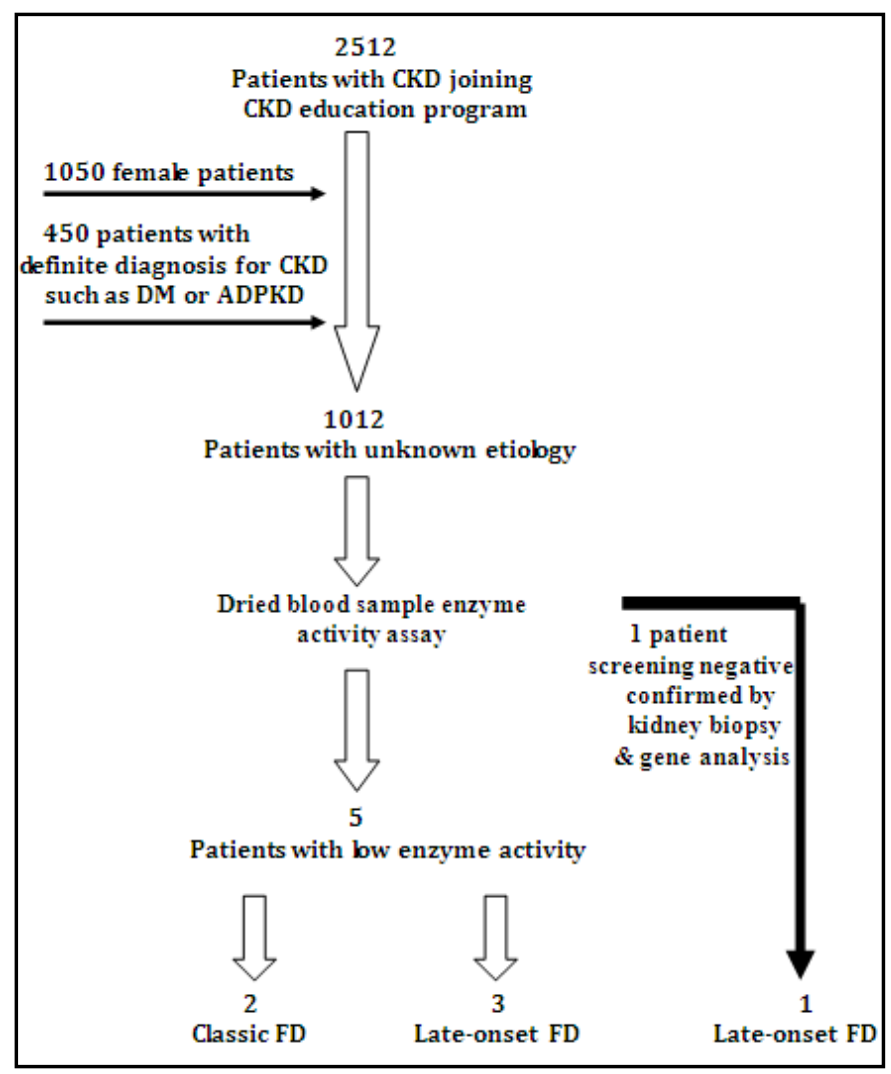

Fig. 1. Flow diagram and total outcomes of screening of high risk patients with unknown CKD etiology. 


\section{Kidney Blood Pressure Research}

from 0.4 to $6.25 \mathrm{~g}$ per day (mean 2.0 g/day). Three patients presented with microscopic hematuria at diagnosis. Four patients had hypertension. Index patient 4 and 5 were diagnosed as classic FD by genetic analysis and were younger than those with late onset FD. Their clinical presentations were not fully concordant. They developed advanced renal failure earlier and had extrarenal diseases including hypertrophic cardiomyopathy, neuropathy and / or skin lesions. According to medical chart report, both patients had experienced and hospitalized several times with unexplained cerebral infarction, neuropathy and hypertrophic cardiomyopathy at their young age. Index patient 4 had gastrointestinal symptoms and index patient 5 had skin angiokeratoma. Neither index patient 4 nor index patient 5 had ophthalmic lesion. Kidney biopsy was suggested for both patients. Only index patient 5 agreed and had completed kidney biopsy. The pathology showed accumulation of myeloid bodies in podocytes (Fig. 3). The correct diagnosis was delayed for two decades.

However, index patients 2 and 6 were diagnosed with late-onset FD in old age. A cardiac MRI showed septal hypertrophy and intramyocardial fibrosis of the left ventricular wall for both two patients. In addition to an ischemic heart lesion, they also had mild renal function impairment. Index patient 1 was diagnosed very early because he joined screening study at the age of 30 for early CKD and did not have cardiac problem.

In addition, index patient 3 developed proteinuria $(1.2 \mathrm{~g} /$ day $)$ at age of 31 and was enrolled to CKD education program. His FD screening result showed borderline $\alpha$-Gal A activity in the DBS test (GLA $1.03 \mu \mathrm{mol} / \mathrm{L} \mathrm{wb} / \mathrm{hr}$, BGAL/GLA 14.89) and were classified as negative. However, kidney pathology showed some myelin bodies in the podocytes and parietal epithelial cells indicated FD (Fig. 3). Genetic analysis showed a mutation with c.628C > T (p.P210S) compatible with late onset FD. Unfortunately, he lost follow-up

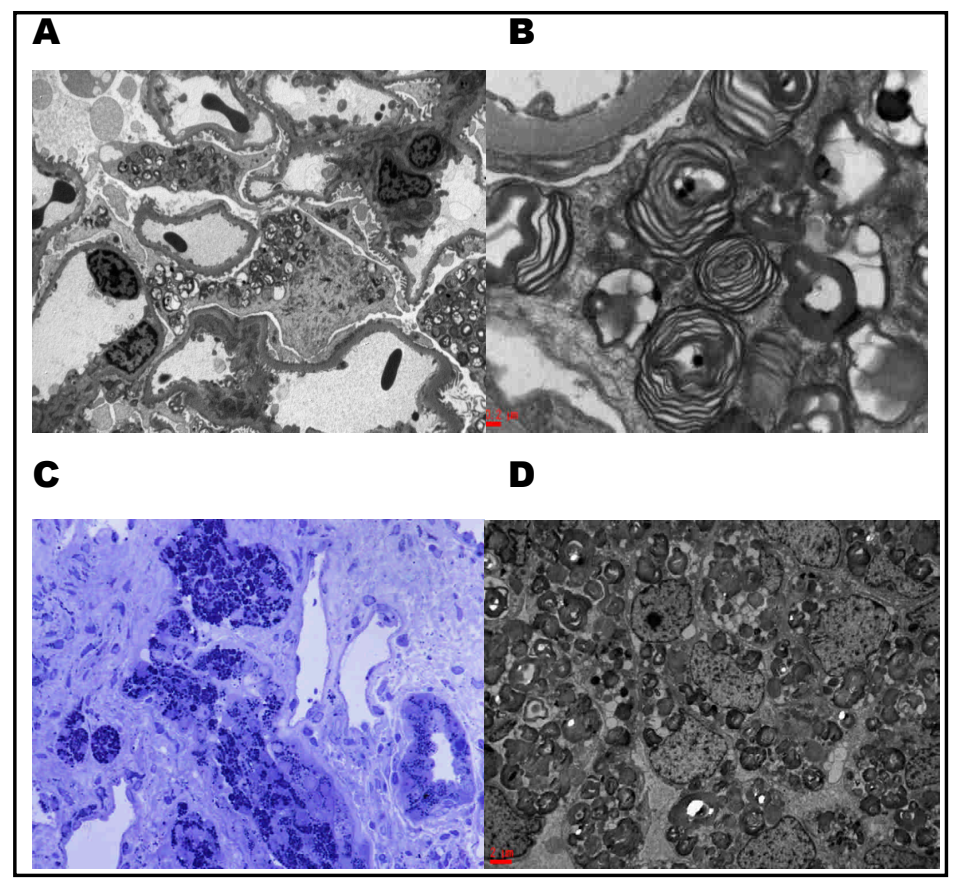

Fig. 2. Kidney pathology from index patient 3 (up) and 5 (below). The accumulation of myeloid bodies in podocyte (A)EM, 2500X, (B)EM,

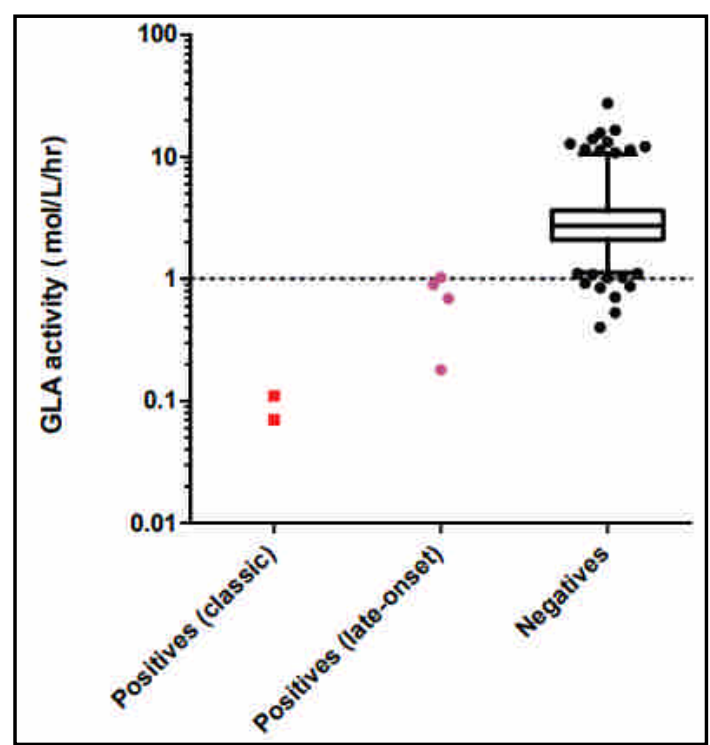

Fig. 3. GLA enzyme activity in patients with CKD by DBS. 


\section{Kidney Blood Pressure Research}

Lin et al.: Fabry Disease in Pre-ESRD

Table 1. Diagnosis, characteristics and clinical presentation in patients with the newly recognized FD. (PS: "-“: negative; NP: not performed; IHD: ischemic heart disease; CHF: congestive heart failure; SSS: sick sinus syndrome; HCM: hypertrophic cardiomyopathy; CAD: coronary artery disease)

\begin{tabular}{|c|c|c|c|c|c|c|c|}
\hline Index Patient & 1 & 2 & 3 & 4 & 5 & 6 & Mean \pm SD \\
\hline Age (yrs) & 30 & 82 & 31 & 43 & 56 & 71 & $52.2 \pm 21.4$ \\
\hline CKD stage at diagnosis & 2 & $3 \mathrm{~b}$ & 2 & 5 & 3 & 3 & \\
\hline eGFR $(\mathrm{ml} / \mathrm{min})$ & 85 & 39 & 82 & 12 & 42 & 43 & $50.5 \pm 28.0$ \\
\hline Daily protein loss (g) & 0.7 & 0.6 & 0.6 & 6.25 & 0.4 & 3.6 & $2.0 \pm 2.4$ \\
\hline Microscopic hematuria & - & $\mathrm{Y}$ & - & $\mathrm{Y}$ & $\mathrm{Y}$ & - & \\
\hline Hypertension & - & $\mathrm{Y}$ & - & $\mathrm{Y}$ & $\mathrm{Y}$ & $\mathrm{Y}$ & \\
\hline Heart disease & - & IHD & - & $\mathrm{CHF} / \mathrm{HCM}$ & SSS/HCM & CAD & \\
\hline Angiokeratoma & - & - & - & - & Y & - & \\
\hline Neuropathy & - & - & - & $\mathrm{Y}$ & $\mathrm{Y}$ & - & \\
\hline Eye abnormalities & - & - & - & - & - & - & \\
\hline Gastrointestinal symptoms & - & - & - & $\mathrm{Y}$ & - & - & \\
\hline Stroke & - & - & - & $\mathrm{Y}$ & $\mathrm{Y}$ & - & \\
\hline Time (yrs) of first symptoms till & 0.2 & 15 & 0.4 & 20 & 20 & 8 & $10.6 \pm 9.1$ \\
\hline DBS GLA activity $(\mu \mathrm{mol} / \mathrm{L} w \mathrm{~b} / \mathrm{hr})$ & 0.18 & 0.69 & 1.03 & 0.07 & 0.11 & 0.90 & \\
\hline GLA Mutation & c. $639+919 \mathrm{G}>\mathrm{A}$ & c. $639+919 \mathrm{G}>\mathrm{A}$ & c. $628 \mathrm{C}>\mathrm{T}$ & c. $1228 \mathrm{~A}>\mathrm{G}$ & c. $413 \mathrm{G}>\mathrm{A}$ & c. $639+919 \mathrm{G}>\mathrm{A}$ & \\
\hline Phenotype & Late-onset & Late-onset & Late-onset & Classic & Classic & Late-onset & \\
\hline Kidney biopsy & NP & NP & Myelin body & NP & Myelin body & NP & \\
\hline Affected relatives & $?$ & 2 & $?$ & 0 & 1 & - & \\
\hline On dialysis & - & - & - & $\mathrm{Y}$ & - & & \\
\hline ERT & - & $\mathrm{Y}$ & - & $\mathrm{Y}$ & $\mathrm{Y}$ & - & \\
\hline
\end{tabular}

without any information after final diagnosis. No extra-renal lesion except cardiac lesion (index patient 2 and 6) was noted for these with late onset of FD. The mean time of first symptom developed until final definite diagnosis was 10.6 years for these 6 patients. Family screenings of these index patients were suggested and performed as enzyme analysis in DBS and genetic testing. Only index patient 2, 4, 5 and 6 and their families agreed to do further screening for FD and the results were showed in Fig. 4. Average two another two patients were found from family screening through a new index.

\section{Discussion}

To the best of our knowledge, this is the first study to explore the prevalence of FD in high-risk patients with male CKD with unknown cause through the platform of the CKD education project in Asia. Our screening results indicated that FD prevalence $(0.59 \%)$ is high among this population. The highly variable phenotype in FD increased the difficulty in recognizing this condition.

The incessant growth of ESRD will lead to a global health burden. Taiwan had the highest incidence and prevalence rate of ESRD according to the USRDS report. The first step in preventing renal function progression is to look for the definite etiology of CKD. Little is known about the causes of CKD of uncertain etiology (CKD u) around the world. Early identification of the etiologies of CKD u across high-risk populations may help to maintain renal function in CKD patients. Patients with FD are at high risk for developing CKD or even ESRD. Diabetes mellitus, chronic glomerulonephritis and hypertension are the predominant causes of ESRD in the world [20].

However, a certain percentage of patients have an unknown etiology of ESRD [21]. A couple of studies investigated the frequency of FD in dialysis [12-14, 22-25] and the results showed that the average prevalence rate of FD in dialysis was about $0.37 \%$ [26]. It was too late to diagnose new FD patients until they were on HD. However, this situation can be reversed by the introduction of widespread screening for the population at risk. From our results, the diagnosis of FD made several years later after the first symptoms developed, was compatible with other investigations [13,27]. Patients with a delayed diagnosis will develop more complications, have a poor response to ERT treatment and often die due to cardiac failure in their 40s [28]. Early diagnosis will change patients' outcomes. This concept can be applied to the prevention and treatment in CKD. FD is a potential risk factor that leads to ESRD. Thus, we try to explore the exact frequency of FD in male CKD patients with unknown causes through the platform of CKD prevention program. 
Index patient 2

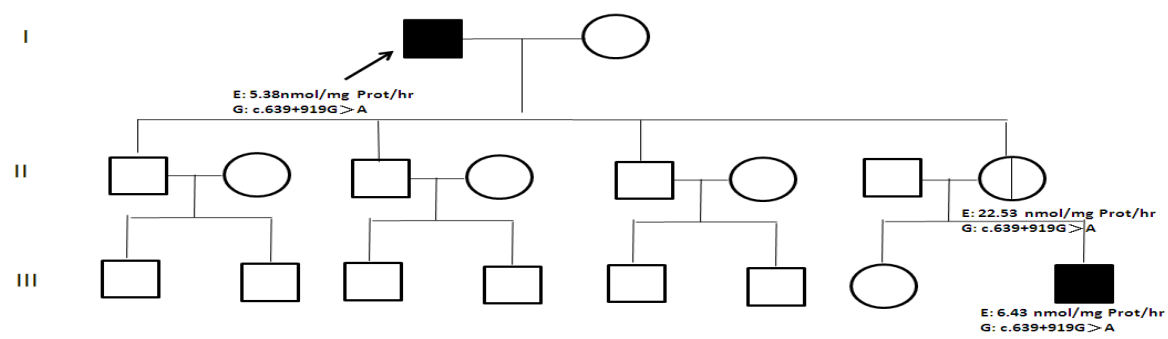

Index patient 4

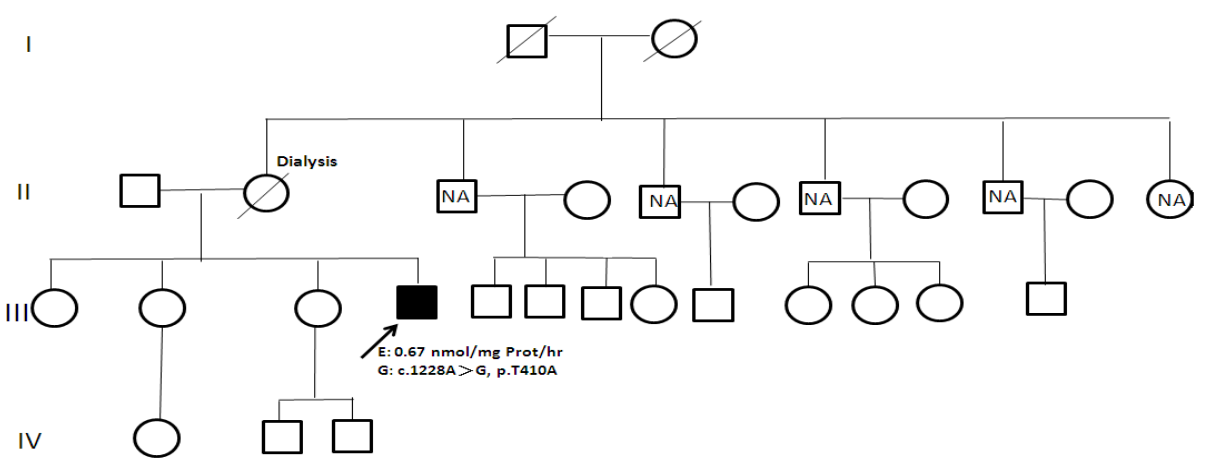

Index patient 5

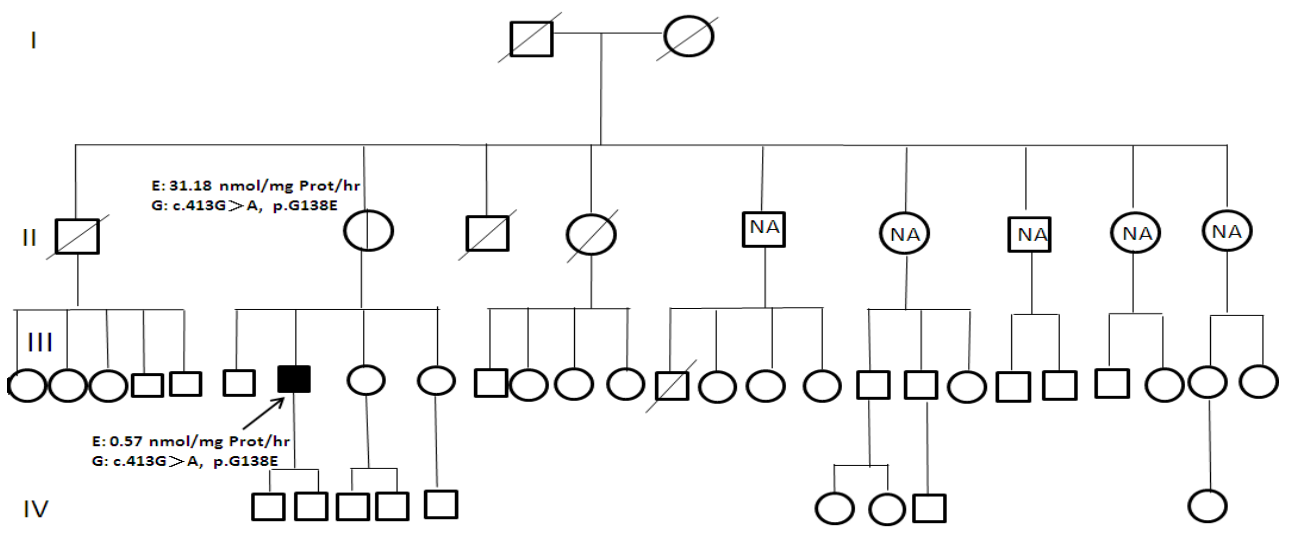

Index patient 6

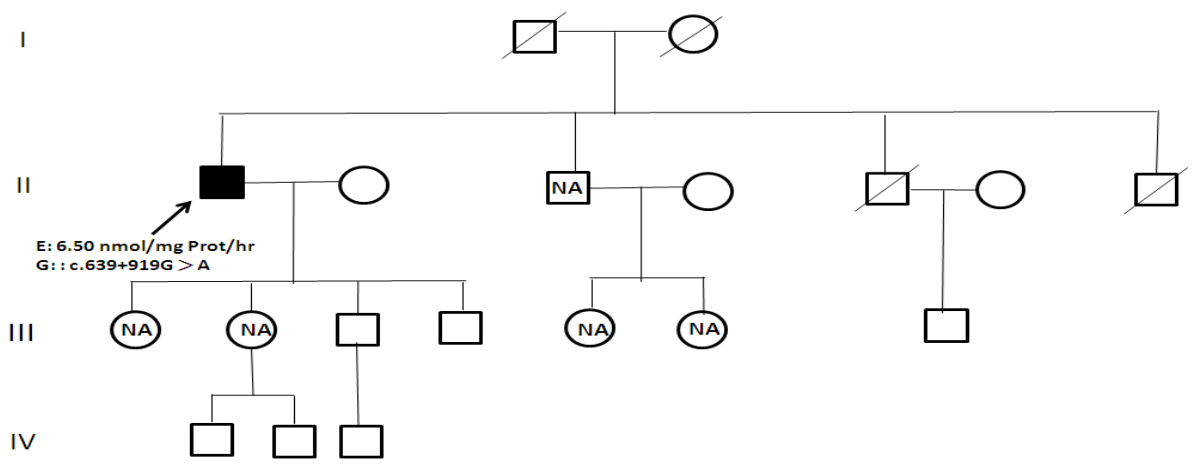

Fig. 4. The results of family screening and pedigree from index patient $2,4,5$ and 6 . The index patient is marked by an oblique arrow. (PS: E: leukocyte enzyme activity; G: genotype; NA: not check) 


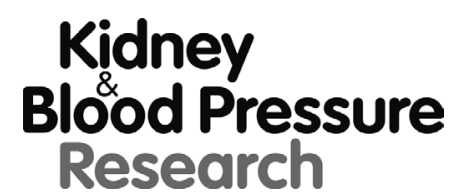

Kidney Blood Press Res 2018;43:1636-1645

DOI: $10.1159 / 000494678$

Published online: 29 October 2018

(C) 2018 The Author(s). Published by S. Karger AG, Basel

www.karger.com/kb

Lin et al.: Fabry Disease in Pre-ESRD

The worldwide frequency of FD in CKD is not clear. Previous epidemiological study results showed the frequency of FD to be about one in 1, 250 male newborns [17]. The prevalence of FD in this study was $0.59 \%$. Our results indicated that FD prevalence was high, especially in the high-risk population. There were two and four patients confirmed as classical FD and late onset of FD, respectively. Patients with classic FD will present first with cardiac arrhythmia, LVH, early stoke and unknown etiology of renal failure. The extra kidney and cardiac symptoms were not always present in our classic FD patients. The ocular lesion cannot be found in these patients. Only index patient 5 had atypical skin angiokeratoma. However, the GLA mutation with c. $413 \mathrm{G}>\mathrm{A}$ in this patient was a novel missense mutation, which has been reported in Germany and the USA [29, 30]. Interestingly, he presented with an unusual symptom - lymphedema for 20 years and the accurate diagnosis was delayed until he developed renal failure, stroke, and arrhythmia.

However, four patients had late-onset FD including index 2 and 6 diagnosed at a late age and index 1 and 3 diagnosed at a young age by a DBS test. Three of the 4 late-onset FD patients had a GLA mutation in c.639+919 G>A, a popular mutation site found in studies of male newborns screening for cardiac variant FD in Taiwan [17, 31]. This result indicated that the mutation in IVS4+919G $\rightarrow$ A will be high in adults, which is also compatible with the results showing the high prevalence of late-onset FD in our screening. In addition to CKD, patient with young stroke as well as unknown etiology of cardiac arrhythmia or LVH were high risk for FD $[7,32,33]$. Thus, screening in these populations was essential to an early diagnosis of FD. Evidence from a clinical study with 10 years of follow-up showed that earlier treatment intervention supported a better response for kidney function maintenance [29].

From our results, all patients with low GLA enzymatic activity screened by initial DBS can be confirmed as having FD by further genetic analysis. However, a false negative result was noted in this screening for one patient (index patient 3) who was negative by DBS and proved to have FD by kidney pathology. Tanakahashi $\mathrm{N}$ et al. reported that a middle-aged woman with normal GLA enzyme activity was diagnosed with FD by kidney pathology [34]. For a heterozygous female, $\mathrm{X}$ chromosome inactivation means there is no clear association between clinical symptoms and GLA enzyme activity [35]. In female FD patients, the enzymatic activity can be normal or slightly lower. Having this false-negative result was extremely rare in our screening study. In addition to a good screening method, tissue pathology from the kidney or heart was essential to further and together confirm the diagnosis of FD.

Our study had some limitations. First, our study did not include female CKD patients because their GLA enzyme activity might not be sensitive to the initial DBS test. Second, this high-risk screening study was carried out in only one medical center in Northern Taiwan, not nationwide. It was therefore unable to completely reflect the true prevalence and distribution of FD in CKD in our country. Third, we did not report patients' long-term outcomes and their response to ERT. Finally, we don't have kidney biopsy from those IVS 4+919G>A patients to confirm if their CKD is related to this low GLA activity. Thus, additional prospective investigations are required to further address these intriguing questions.

\section{Conclusion}

Our study demonstrates the feasibility to investigate the prevalence of FD in high-risk patients with male CKD from the platform of the CKD education project in Asia. We point out that the prevalence of FD is much higher than we expected in this population. Although the screening of FD in dialysis patients is suggested by the guidelines from KDIGO [36], we think the screening should be done earlier and extended to pre-ESRD patients without definite cause for renal impairment. Clinicians need to be aware that FD should be included in the differential diagnosis in high-risk patients. Timely detection of FD and treatment may avoid the development of serious complications in the future, and also benefit to other families. 


\section{Kidney \\ Blood Pressure Research}

Lin et al.: Fabry Disease in Pre-ESRD

\section{Acknowledgements}

We would like to thank all the patients who were involved in this study. The screening study was supported with an educational grant from Sanofi. The sponsor had no role in data collection, interpretation or treatment strategy.

\section{Disclosure Statement}

The authors declare no conflicts of interest.

\section{References}

1 Kint JA: Fabry's disease: alpha-galactosidase deficiency. Science 1970;167:1268-1269.

-2 Brady RO, Gal AE, Bradley RM, Martensson E, Warshaw AL, Laster L: Enzymatic defect in Fabry's disease Ceramidetrihexosidase deficiency. N Engl J Med 1967;276:1163-1167.

-3 Toyooka K: Fabry disease. Curr Opin Neurol 2011;24:463-468.

-4 Bethune JE, Landrigan PL, Chipman CD: Angiokeratoma Corporis Diffusum Universale (Fabry's Disease) in Two Brothers. N Engl J Med 1961;264:1280-1285.

-5 Branton MH, Schiffman NR, Sabnis SG, Murray GJ, Quirk JM, Altarescu G, Goldfarb L, Brady RO, Balow JE, Austin HA, Kopp JB: Natural history of Fabry renal disease: influence of alpha-galactosidase A activity and genetic mutations on clinical course. Medicine (Baltimore) 2002;81:122-138.

6 Wanner C, Oliveira JP, Ortiz A, Mauer M, Germain DP, Gabor E, Linthorst GE, Andreas L, Serra AL, Maródi L, Mignani R, Cianciaruso B, Vujkovac B, Lemay R, Beitner-Johnson D, Waldek S, Warnock DG: Prognostic indicators of renal disease progression in adults with Fabry disease: natural history data from the Fabry Registry. Clin J Am Soc Nephrol 2010;5:2220-2228.

7 Kampmann C, Baehner F, Ries M, Beck M: Cardiac involvement in Anderson-Fabry disease. J Am Soc Nephrol 2002;13:S147-S149.

-8 Efthimiou J, McLelland J, Betteridge DJ: Short PR intervals and tachyarrhythmias in Fabry's disease. Postgrad Med J 1986;62:285-287.

-9 Sims K, Politei J, Banikazemi M, Lee P: Stroke in Fabry disease frequently occurs before diagnosis and in the absence of other clinical events: natural history data from the Fabry Registry. Stroke 2009;40:788-794.

$\checkmark 10$ Mehta A, Ricci R, Widmer U, Dehout F, Garcia de Lorenzo A, Kampmann C, Linhart A, Sunder-Plassmann G, Ries M, Beck M: Fabry disease defined: baseline clinical manifestations of 366 patients in the Fabry Outcome Survey. Eur J Clin Invest 2004;34:236-242.

$\checkmark 11$ Sodré LSS, Huaira RMNH, Bastos MG, Colugnati FAB, Coutinho MP, Fernandes NMDS: Screening for Fabry Disease in Kidney Disease: a Cross-Sectional Study in Males and Females. Kidney Blood Press Res 2017;42:1258-1265.

-12 Linthorst GE, Hollak CE, Korevaar JC, Van Manen JG, Aerts JM, Boeschoten EW: Alpha-galactosidase A deficiency in Dutch patients on dialysis: A critical appraisal of screening for Fabry disease. Nephrol Dial Transplant 2003;18:1581-1584.

13 Kotanko P, Kramar R, Devrnja D, Paschke E, Voigtlander T, Auinger M, Pagliardini S, Spada M, Demmelbauer K, Lorenz M, Hauser AC, Kofler HJ, Lhotta K, Neyer U, Pronai W, Wallner M, Wieser C, Wiesholzer M, Zodl H, Fodinger M: Results of a nationwide screening for Anderson-Fabry disease among dialysis patients. J Am Soc Nephrol 2004;15:1323-1329.

$\checkmark 14$ Nakao S, Kodama C, Takenaka T, Tanaka A, Yasumoto Y, Yoshida A, Kanzaki T, Enriquez AL, Eng CM, Tanaka H, Tei C, Desnick RJ: Fabry disease: Detection of undiagnosed hemodialysis patients and identification of a "renal variant" phenotype. Kidney Int 2003;64:801-807.

-15 Kosch M, Koch HG, Oliveira JP, Soares C, Bianco F, Breuning F, Rasmussen AK, Schaefer RM: Enzyme replacement therapy administered during hemodialysis in patients with Fabry disease. Kidney Int 2004;66:1279-1282.

-16 Lin YC, Hsu CY, Kao CC, Chen TW, Chen HH, Hsu CC, Wu MS: Incidence and prevalence of ESRD in Taiwan Renal Registry Data System (TWRDS): 2005-2012. Acta Nephrol 2014;28:65-68. 


\section{Kidney \\ Blood Pressure Research}

Kidney Blood Press Res 2018;43:1636-1645

\begin{tabular}{l|l}
\hline DOI: $10.1159 / 000494678$ & (c) 2018 The Author(s). Published by S. Karger AG, Base
\end{tabular}

Published online: 29 October 2018

www.karger.com/kbr

Lin et al.: Fabry Disease in Pre-ESRD

17 Hwu WL, Chien YH, Lee NC, Chiang SC, Dobrovolny R, Huang AC, Yeh HY, Chao MC, Lin SJ, Kitagawa T, Desnick RJ, Hsu LW: Newborn screening for Fabry disease in Taiwan reveals a high incidence of the lateronset GLA mutation c.936+919G>A (IVS4+919G>A). Hum Mutat 2009;30:1397-1405.

$>18$ Chien YH, Lee NC, Chiang SC, Desnick RJ, Hwu WL: Fabry disease: incidence of the common later-onset $\alpha$-galactosidase A IVS4+919G>A mutation in Taiwanese newborns--superiority of DNA-based to enzymebased newborn screening for common mutations. Mol Med 2012;18:780-784.

19 Zhang XK, Elbin CS, Chuang WL, Cooper SK, Marashio CA, Beauregard C, Keutzer JM: Multiplex enzyme assay screening of dried blood spots for lysosomal storage disorders by using tandem mass spectrometry. Clin Chem 2008;54:1725-1728.

-20 Jha V, Garcia-Garcia G, Iseki K, Li Z, Naicker S, Plattner B, Saran R, Wang AY, Yang CW: Chronic kidney disease: global dimension and perspectives. Lancet 2013;382:260-272.

-21 Lunyera J, Mohottige D, Von Isenburg M, Jeuland M, Patel UD, Stanifer JW: CKD of Uncertain Etiology: A Systematic Review. Clin J Am Soc Nephrol 2016;11:379-385.

-22 Ichinose M, Nakayama M, Ohashi T, Utsunomiya Y, Kobayashi M, Eto Y: Significance of screening for Fabry disease among male dialysis patients. Clin Exp Nephrol 2005;9:228-232.

-23 Merta M, Reiterova J, Ledvinova J, Poupětová H, Dobrovolný R, Ryšavá R, Maixnerová D, Bultas J, Motáň J, Slivkova J, Sobotova D, Smrzova J, Tesař V: A nationwide blood spot screening study for Fabry disease in the Czech Republic haemodialysis patient population. Nephrol Dial Transpl 2007;22:179-186.

24 Doi K, Noiri E, Ishizu T, Negishi K, Suzuki Y, Hamasaki Y, Honda K, Fujita T, Tsukimura T, Togawa T, Saito S, Sakuraba H: High-throughput screening identified disease-causing mutants and functional variants of agalactosidase A gene in Japanese male hemodialysis patients. J Hum Genet 2012;57:575-579.

25 Maruyama H, Takata T, Tsubata Y, Tazawa R, Goto K, Tohyama J, Narita I, Yoshioka H, Ishii S: Screening of male dialysis patients for Fabry disease by plasma globotriaosylsphingosine. Clin J Am Soc Nephrol 2013;8:629-636.

-26 Saito O, Kusano E, Akimoto T, Asano Y, Kitagawa T, Suzuki K, Ishige N, Akiba T, Saito A, Ishimura E, Hattori M, Hishida A, Guili C, Maruyama H, Kobayashi M, Ohashi T, Matsuda I, Eto Y: Prevalence of Fabry disease in dialysis patients: Japan Fabry disease screening study (J-FAST). Clin Exp Nephrol 2016;20:284-293.

27 Brady M, Montgomery E, Brennan P, Mohindra R, Sayer JA: Diagnosing Fabry disease - delays and difficulties within discordant siblings. QJM 2015;108:585-590.

28 Antonino T, Rosaria P, Irene S, Salvatore M, Antonio P, Giuseppe L: Anderson-Fabry disease: a multiorgan disease. Curr Pharm 2013;19:5974-5996.

-29 Germain DP, Charrow J, Desnick RJ, Guffon N, Kempf J, Lachmann RH, Lemay R, Linthorst GE, Packman S, Scott CR, Waldek S, Warnock DG, Weinreb NJ, Wilcox WR: Ten-year outcome of enzyme replacement therapy with agalsidase beta in patients with Fabry disease. J Med Genet 2015;52:353-358.

-30 Terryn W, Poppe B, Wuyts B, Claes K, Maes B, Verbeelen D, Vanholder R, De Boeck K, Lameire N, De Paepe A, De Schoenmakere G: Two-tier approach for the detection of alpha-galactosidase A deficiency in predominantly female haemodialysis population. Nephrol Dial Transplant 2008;23:294-300.

-31 Lin HY, Chong KW, Hsu JH, Yu HC, Shih CC, Huang CH, Lin SJ, Chen CH, Chiang CC, Ho HJ, Lee PC, Kao $\mathrm{CH}$, Cheng KH, Hsueh C, Niu DM: High incidence of cardiac variant of Fabry disease revealed by newborn screening in the Taiwan Chinese population. Circ Cardiovasc Genet 2009;2:450-456.

-32 Shi Q, Chen J, Pongmoragot J, Lanthier S, Saposnik G: Prevalence of Fabry disease in stroke patients--a systematic review and meta-analysis. J Stroke Cerebrovasc Dis 2014;23:985-992.

33 Sachdev B, Takenaka T, Teraguchi H, Tei C, Lee P, McKenna WJ, Elliott PM: Prevalence of Anderson-Fabry disease in male patients with late onset hypertrophic cardiomyopathy. Circulation 2002;105:1407-1411.

-34 Takahashi N, Yokoi S, Kasuno K, Kogami A, Tsukimura T, Togawa T, Saito S, Ohno K, Hara M, Kurosawa H, Hirayama Y, Kurose T, Yokoyama Y, Mikami D, Kimura H, Naiki H, Sakuraba H, Iwano M: A heterozygous female with Fabry disease due to a novel $\alpha$-galactosidase A mutation exhibits a unique synaptopodin distribution in vacuolated podocytes. Clin Nephrol 2015;83:301-308.

-35 Juchniewicz P, Kloska A, Tylki-Szymańska A, Jakóbkiewicz-Banecka J, Węgrzyn G, Moskot M, Gabig-Cimińska M, Piotrowska E: Female Fabry disease patients and X-chromosome inactivation. Gene 2018;641:259-264.

-36 Terryn W, Cochat P, Froissart R, Ortiz A, Pirson Y, Poppe B, Serra A, Van Biesen W, Vanholder R, Wanner C: Fabry nephropathy: indications for screening and guidance for diagnosis and treatment by the European renal best practice. Nephrol Dial Transplant 2013;28:505-517. 